\title{
A biomechanical analysis of triangular medial knee reconstruction
}

\author{
Xiaomeng Wang, Huixin Liu, Guman Duan, Yingzhen Niu, Chang Liu and Fei Wang ${ }^{*}$
}

\begin{abstract}
Background: The purpose of this study was to evaluate and compare knee kinematics and stability following either triangular or anatomical reconstruction of the superficial medial collateral ligament (SMCL) and posterior oblique ligament (POL).

Methods: In a cadaveric model (12 knees), the stability and kinematics following two experimental SMCL and POL reconstructions were compared in SMCL- and POL-deficient knees versus normal knees. The first reconstruction was a triangular reconstruction of the $S M C L$ and $\mathrm{POL}$, while the second involved an anatomical reconstruction of the SMCL and POL. All knees were tested through four different states. The changes in valgus angles, external rotation, and internal rotation were measured in the normal and SMCL- and POL-deficient knees, as well as in the knees that had undergone the two different forms (triangular and anatomical) of reconstruction.

Results: After initial sectioning of the $S M C L$ and $P O L$, we observed significantly increased valgus rotation, external rotation, and internal rotation at all knee flexion angles $\left(0^{\circ}, 20^{\circ}, 30^{\circ}, 60^{\circ}, 90^{\circ}\right)$. Additionally, passive stability testing demonstrated a significant increase in tibial internal rotation following triangular reconstruction compared with anatomical reconstruction at knee flexion angles of $20^{\circ}$ and $30^{\circ}$. A significant increase in internal rotation was present following triangular reconstruction compared with anatomical reconstruction at $20^{\circ}$ (mean difference $\left.=2.77\right)(P=0.008)$ and $30^{\circ}$ (mean difference $\left.=0.99\right)(P<0.001)$ of knee flexion.
\end{abstract}

Conclusion: This study suggests that anatomical SMCL and POL reconstruction produces slightly better biomechanical stability than triangular reconstruction. However, triangular reconstruction may restore a near-normal knee joint is both less invasive and more practical.

Keywords: Superficial medial collateral ligament, Posterior oblique ligament, Triangular reconstruction, Anatomical reconstruction, Stability

\section{Background}

Isolated medial collateral ligament (MCL) injury often does not require surgical treatment [1-3]. However, severe MCL injuries are often accompanied by injury to the posteromedial structures of the knee [4]. Halinen [5] and Indelicato [3] suggested that injuries to the posteromedial structures can heal with conservative treatment, but they may result in residual joint laxity and increased rotation, which can lead to osteoarthritis and eversion in the long term [6]. Thus, early surgery should be considered in patients with severe posteromedial structure injuries [7].

\footnotetext{
* Correspondence: doctorwf@yeah.net; 18633835079@yeah.net Department of Orthopaedic Surgery, Third Hospital of Hebei Medical University, No.139 Ziqiang Road, Shijiazhuang 050051, Hebei, China
}

The posteromedial structures are extremely important to valgus and rotational stability of the knee. The superficial MCL (sMCL) plays a major role in valgus stability of the knee joint, and a secondary role in internal and external rotation stability $[8,9]$. The posterior oblique ligament $(\mathrm{POL})$ has an important function in rotational stability, and a secondary function in valgus and external rotation stability [10-12]. From a biomechanical point of view, the sMCL contributes $78 \%$ of the stability in valgus and external rotation at $25^{\circ}$ of knee flexion, and the POL plays a primary role in internal rotation and preventing valgus when knee flexion is between $0^{\circ} \sim 30^{\circ}[8,13]$. Thus, it is clear that repairing the sMCL and POL efficiently simultaneously plays a dominant role in the stability and biomechanics of the knee joint [6].

(c) The Author(s). 2018 Open Access This article is distributed under the terms of the Creative Commons Attribution 4.0 International License (http://creativecommons.org/licenses/by/4.0/), which permits unrestricted use, distribution, and reproduction in any medium, provided you give appropriate credit to the original author(s) and the source, provide a link to the Creative Commons license, and indicate if changes were made. The Creative Commons Public Domain Dedication waiver (http://creativecommons.org/publicdomain/zero/1.0/) applies to the data made available in this article, unless otherwise stated. 
Slocum [14], Hughston [15], and Fanelli [16] highlighted the importance of tight suturing of the posteromedial capsule and the POL when reconstructing the sMCL. Lind [17], Coobs [18], and Azar [19] both described operative methods for double-bundle reconstruction of the SMCL and POL in treating chronic damage to the posteromedial structures of the knee. Coobs [18] confirmed in an in vitro biomechanical study that normal medial knee stability can be restored by reconstructing the sMCL and POL at their anatomical attachment points. Feeley confirmed that reconstructing the sMCL based on its anatomical footprint led to the smallest biomechanical variation [20]. Thus, the consensus has been that anatomical reconstruction of the sMCL is the optimal approach. The POL is an important ligament as well, but the effects of changing its attachment point are not well understood.

With anatomical reconstruction of the sMCL and POL, four tunnels, four interface screws, and two ligaments are used [18]. The triangular reconstruction method was created based on traditional clinical operative methods. Two femoral bone tunnels and two tibial bone tunnels are each substituted with one tunnel. The outcomes following use of this method have not been well demonstrated in experimental or clinical studies.

The purpose of our study was to compare the stability and kinematics following either triangular or anatomical reconstruction of the $\mathrm{SMCL}$ and POL in a cadaveric model. We hypothesized that the triangular technique would yield similar efficacy compared with anatomical reconstruction of the SMCL and POL.

\section{Methods}

\section{Specimen materials}

Twelve fresh-frozen cadaveric knees were used in the current study. Specimens with ligamentous laxity, severe arthritis, or previous surgery were excluded. The cadaveric knees averaged 51.3 years of age, and included eight males and four females, three left knees, five right knees. All of the specimens were provided by the third Affiliated Hospital of Hebei Medical University. Informed consent to participate in the study was obtained from the patients, and written consent was obtained from the patients before they died to use their knees after death. All knee joints were thawed $24 \mathrm{~h}$ before being processed. The femur and tibia were removed $25 \mathrm{~cm}$ above and below the joint line, and then were fixed together with a steel wire.

\section{Testing methods}

All knees were tested in four different states. The changes in valgus, external rotation, and internal rotation were measured in normal and SMCL- and POLdeficient knees, as well as in those that had undergone triangular and anatomical reconstructions (valgus moment of $10 \mathrm{~N} . \mathrm{m}$, internal rotation of $5 \mathrm{~N} . \mathrm{m}$, and external rotation moments were applied to the knee) [18] [Fig. 1] at $0^{\circ}, 20^{\circ}, 30^{\circ}, 60^{\circ}$, and $90^{\circ}$ of knee flexion using a BOSE biomechanical instrument (3520-AT, System 100306, Eden Prairie, MN, USA). Four different types of knees (intact, deficient sMCL and POL, triangular reconstruction, and anatomical reconstruction) were compared in this study. The knees were first tested in the intact state, then tested in the deficient state, then followed by the triangular reconstruction and anatomical reconstruction states. Biomechanical testing was repeated to measure the changes in angles in the four different states.

\section{Allogeneic tendon preparation}

One allogeneic tendon was thawed in physiological saline for $20 \mathrm{~min}$, and its length and diameter were measured. (Length $\geq 20 \mathrm{~cm}$, diameter $4-5 \mathrm{~mm}$ ). A $2.5-\mathrm{cm}$ lock-stitch suture was made at the thicker end of

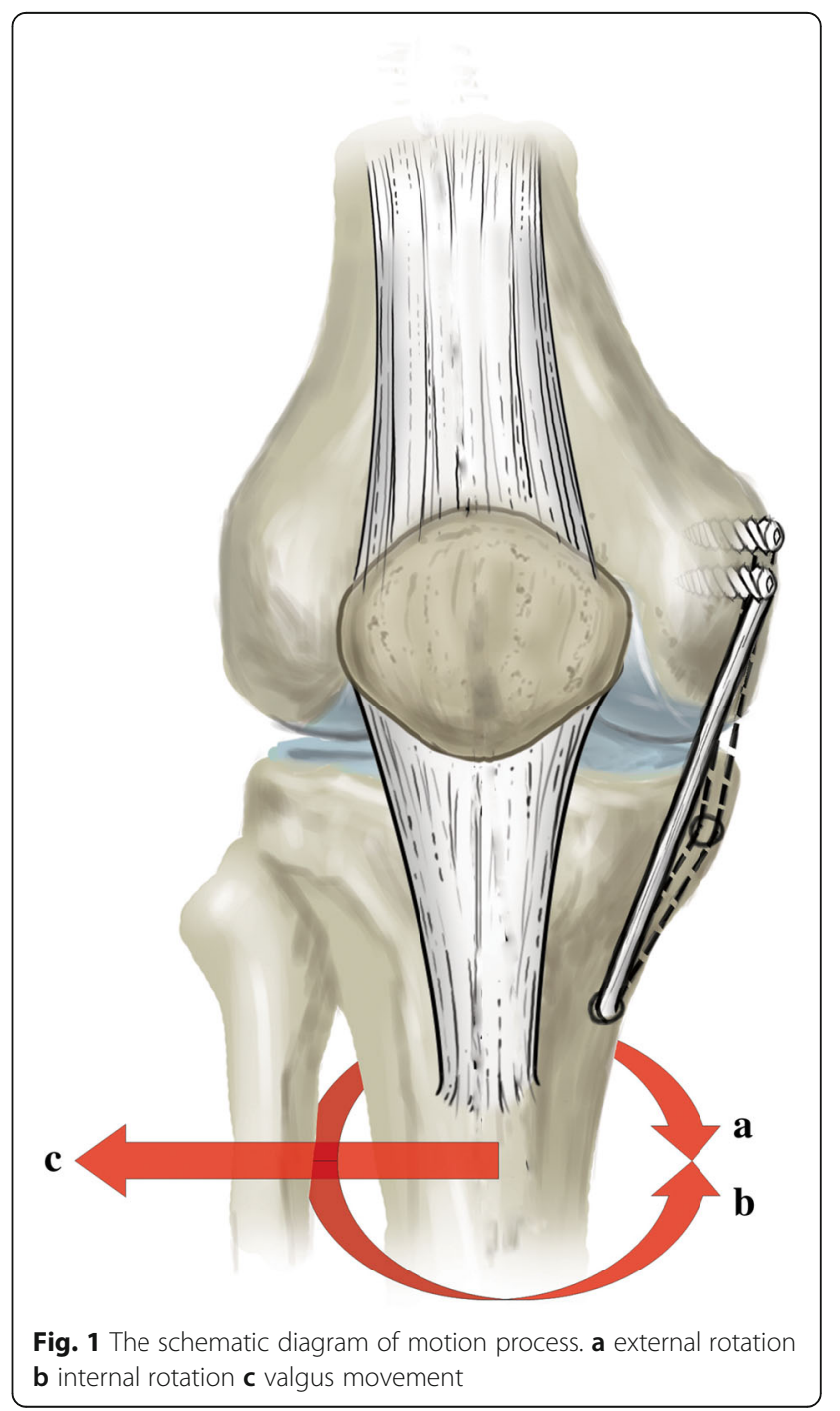



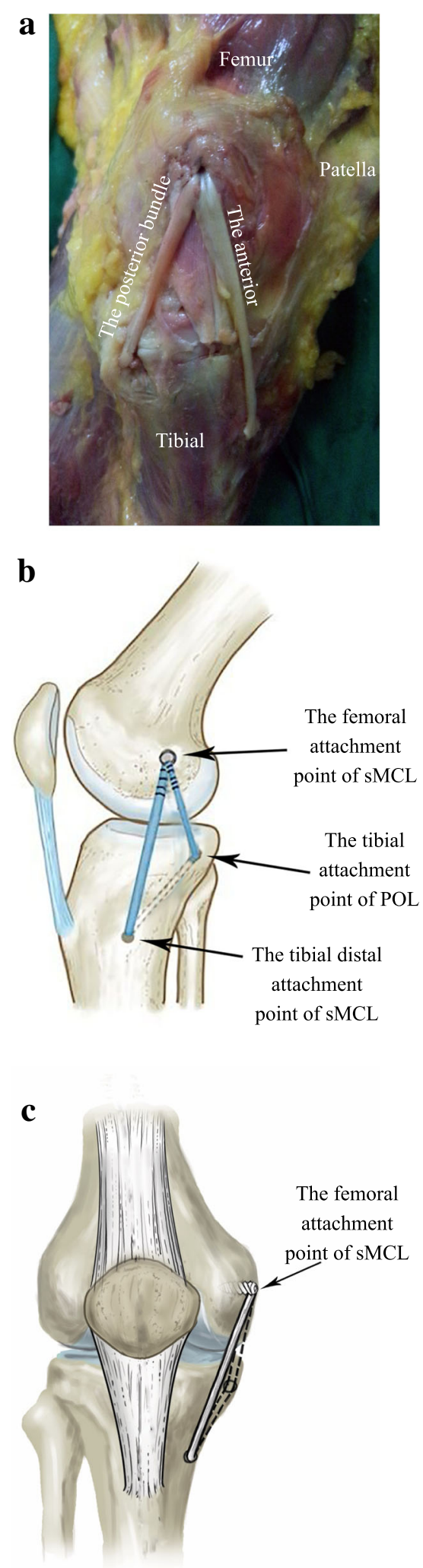

Fig. 2 Triangular reconstruction of the SMCL and POL. The femoral attachment site of the reconstructed SMCL is the $S M C L$ anatomical attachment point. The femoral attachment site of the reconstructed POL is the $S M C L$ anatomical attachment point. The tibial fixation points are the distal $S M C L$ and $P O L$ anatomical attachment points. The reconstructed ligament forms a triangle. a The medial view of the experimental image. $\mathbf{b}$ Schematic diagram viewed from the side. c Schematic diagram viewed from the front

allogeneic tendon with No. 1 suture (Ethibond Excel 4.0 metric). 2-0 Ethicon Vicryl was prepared for use as a pull wire after measuring the diameter of the sutured tendon. A 2.5-cm lock-stitch suture was made at each portion of allogeneic tendon with No. 1 suture (Ethibond Excel 4.0 metric) [18].

\section{Triangular reconstruction technique}

A medial incision was made from the medial femoral epicondyle to the medial proximal tibia to expose the entire MCL and POL. The femoral and tibial anatomical attachment points of the SMCL and POL were exposed by blunt dissection. The sMCL has two attachment points on the tibial side, one located about $1 \mathrm{~cm}$ away from the joint line, and another located about $6 \mathrm{~cm}$ away from the joint [21]. The anterior bundle was the distal tibial attachment of the SMCL; the posterior bundle was the tibial attachment of the POL [21]. We flexed the knee $30^{\circ}$ and used an anterior cruciate ligament reconstruction tibial locator to locate the tibia accurately. We then threaded an eyelet pin as a hook pin from the center of the sMCL tibial insertion to the POL tibial insertion, and used a reamer $(4.5 \mathrm{~mm})$ matched in diameter with the allograft tendon to drill the tibial tunnel along the eyelet pin. After that, we pulled the tendon through the tibial tunnel using a traction wire and threaded an eyelet pin from inside to outside at the sMCL femoral attachment point of the medial femoral condyle. We used the eyelet pin location to determine the length of tendon and wipe off redundant tendon, and then weaved the other side of the tendon $2.5 \mathrm{~cm}$ and continuously sutured the traction wire. We measured the diameter of both distal tendons and selected a reamer $(7 \mathrm{~mm})$ to match with it to drill the femoral tunnel to a depth of $30 \mathrm{~mm}$. We threaded both ends of the tendon under the sartorius tendon and pulled them into the femoral tunnel of the sMCL, and then set the position of the tendon and confirmed that the two beams of the tendon had enough tension while pulling traction on both ends. We flexed the knee joint to $30^{\circ}$ [20], and inserted a bioabsorbable screw tap into the femoral tunnel that matched the diameter of the tunnel (Fig. 2). 


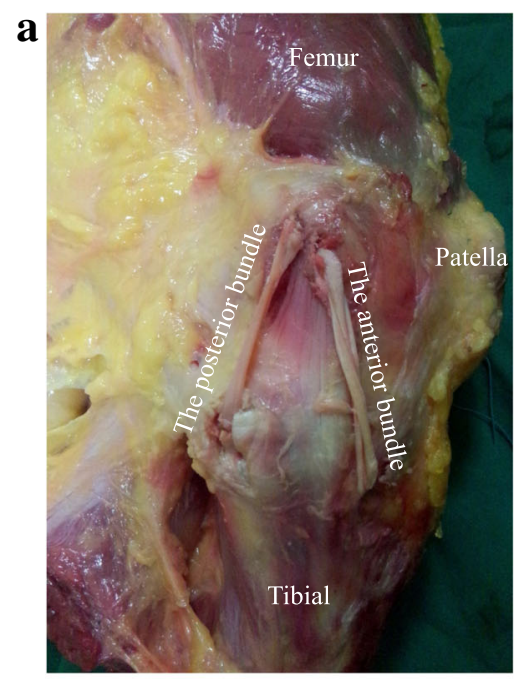

b

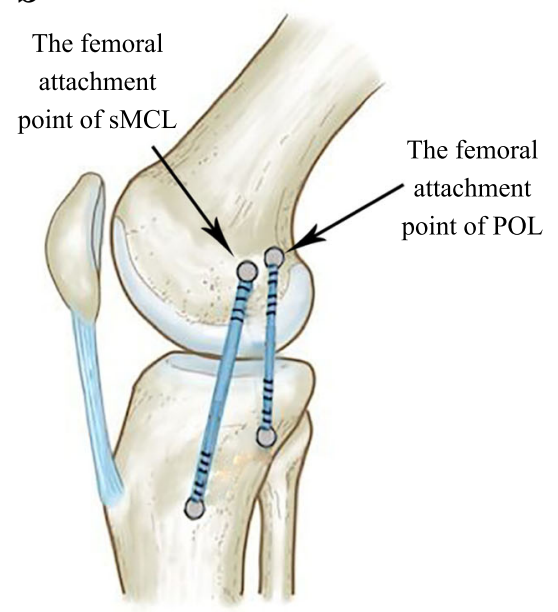

c

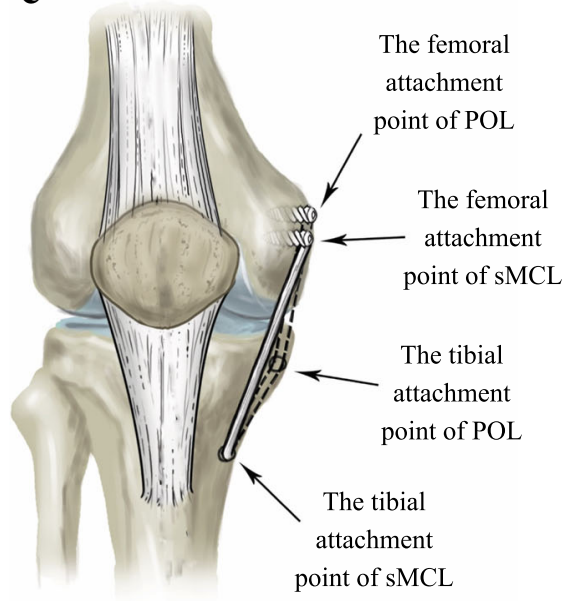

Fig. 3 Anatomical reconstruction $S M C L$ and $P O L$. The femoral attachment sites of the anatomical reconstruction are the SMCL and POL anatomical attachment points. The tibial fixation points are the distal SMCL and POL anatomical attachment points. All reconstructed sites are anatomical sites. a The medial view of the experimental image. b Schematic diagram viewed from the side. c Schematic diagram viewed from the front

\section{Anatomical reconstruction technique}

The anatomical reconstruction technique of the SMCL and POL has previously been described in an article by LaPrade and colleagues [21]. The sMCL and POL were reconstructed with four reconstruction tunnels and four interference screws [18]. In our experiment, three tunnels and two interface screws were used to anatomically reconstruct the SMCL and POL (Fig. 3).

\section{Statistical analysis}

Data were collected using a biomechanical test instrument for measuring the angles of knee extroversion and tibial rotation at different angles of flexion. The results are presented as mean \pm standard deviation. Data processing was performed using SPSS 21.0 (SPSS Inc., Chicago, USA), and the analyses were performed using two-factor analysis of variance. Tests were performed at each knee state $\left(0^{\circ}, 20^{\circ}, 30^{\circ}, 60^{\circ}\right.$, and $90^{\circ}$ of flexion) and measurement index. Factor one was the specimen (nine levels) and factor two was the treatment (four levels). The level of significance was defined as $P<0.05$.

\section{Results}

The biomechanical results of this experiment are listed in Tables 1, 2 and 3.

\section{Valgus rotation}

The changes in the knee joint of each group were observed under a force of 10 N.m. After initial sectioning of the sMCL and POL, we observed significantly increased valgus rotation at all knee flexion angles $\left(0^{\circ}, 20^{\circ}\right.$, $\left.30^{\circ}, 60^{\circ}, 90^{\circ}\right)$. In addition, a significant decrease was observed after sMCL and POL reconstruction compared with the deficient sMCL and POL states at all angles of knee flexion. The mean values of the reconstructed knees were not significantly changed compared with the normal knee at $20^{\circ}, 30^{\circ}, 60^{\circ}, 90^{\circ}$ of knee flexion $(P<0$. $05)$. There were no significant differences when comparing the intact with the triangular or anatomical reconstructions. A significant increase was observed in valgus angulation of the anatomically reconstructed knees compared with the intact reconstructed knees at $0^{\circ}$ of flexion (mean difference $\left.=2.79^{\circ}\right) \quad(P<0.001)$. The mean value $\left(2.66^{\circ}\right)$ of valgus angulation of the triangular reconstruction was significantly different than in the 
Table 1 Valgus angulation with the application of an externally applied load for each testing state

\begin{tabular}{llllll}
\hline Flexion angles & $0^{\circ}$ & $20^{\circ}$ & $30^{\circ}$ & $60^{\circ}$ & $90^{\circ}$ \\
\hline Intact & $3.11 \pm 0.49$ & $5.58 \pm 1.49$ & $7.53 \pm 1.40$ & $9.47 \pm 1.26$ & $10.37 \pm 1.12$ \\
Deficient & $8.89 \pm 1.22^{*}$ & $15.83 \pm 2.20^{*}$ & $16.61 \pm 1.68^{*}$ & $17.87 \pm 1.14^{*}$ & $17.50 \pm 1.18^{*}$ \\
Triangular & $5.87 \pm 0.35^{*}$ & $6.50 \pm 2.14$ & $7.76 \pm 1.02$ & $9.81 \pm 0.80$ & $10.29 \pm 1.24$ \\
Anatomical & $5.90 \pm 0.33^{*}$ & $6.19 \pm 1.86$ & $7.43 \pm 1.09$ & $9.18 \pm 0.80$ & $9.78 \pm 0.79$ \\
\hline
\end{tabular}

Values are presented as mean \pm standard error of the mean

*Significant difference compared with the Intact group $(p<0.05)$

normal knee at $0^{\circ}$ of knee flexion $(P<0.001)$. The mean values of valgus angulation of the triangular reconstruction were not significantly different from the anatomical reconstruction at $0^{\circ}, 20^{\circ}, 30^{\circ}, 60^{\circ}$, and $90^{\circ}$ of knee flexion. No significant differences were observed in tibial valgus rotation of the triangular reconstruction compared with the anatomical reconstruction at $0^{\circ}(P=0$. 908), $20^{\circ}(P=0.699), 30^{\circ}(P=0.540), 60^{\circ}(P=0.131), 90^{\circ}$ $(P=0.255)$ (Fig. 4) (Table 1$)$.

\section{External rotation}

The changes in the knee joint of each group were observed under a force of $5 \mathrm{~N} . \mathrm{m}$. We found a significant increase in external rotation after sectioning the sMCL and POL at all tested knee flexion angles $\left(0^{\circ}, 20^{\circ}, 30^{\circ}\right.$, $\left.60^{\circ}, 90^{\circ}\right)$. In addition, a significant decrease was observed in knees with sMCL and POL reconstruction compared with SMCL- and POL-deficient knees at all angles of knee flexion. The mean external rotation in the triangular or anatomical reconstruction knees were not significantly different than in the intact knee at $0^{\circ}, 20^{\circ}, 30^{\circ}$, $60^{\circ}$, and $90^{\circ}$ of knee flexion $(P<0.05)$ (Fig. 5) (Table 2).

\section{Internal rotation}

The changes in the knee joint of each group were observed under a force of $5 \mathrm{~N}$.m. After initial sectioning of the SMCL and POL, we observed significantly increased internal rotation at all knee flexion angles $\left(0^{\circ}, 20^{\circ}, 30^{\circ}\right.$, $\left.60^{\circ}, 90^{\circ}\right)$. Nevertheless, the mean values of internal rotation following triangular reconstruction were not significantly different compared with normal knees at $0^{\circ}$, $60^{\circ}$, and $90^{\circ}$ of knee flexion $(P<0.05)$. A significant increase was observed in internal rotation of the triangular reconstruction knees compared with the intact reconstruction knees at $20^{\circ}$ (mean difference $\left.=2.77\right)(P=$ $0.008)$ and $30^{\circ}$ (mean difference $\left.=0.99\right)(P<0.001)$ of knee flexion. The mean values of internal rotation following anatomical reconstruction were not significantly different than in the normal knees at $0^{\circ}, 60^{\circ}$, and $90^{\circ}$ of knee flexion $(P<0.05)$. The mean internal rotation $\left(0.93^{\circ}\right)$ with anatomical reconstruction was significantly different from the normal knee at $30^{\circ}$ of knee flexion $(P<0.001)$ (Fig. 6) (Table 3$)$.

\section{Discussion}

The goal of the study was to perform a cadaveric experiment in order to evaluate the kinematics of patients undergoing either anatomical reconstruction or triangular reconstruction of the SMCL and POL. The most significant finding was that anatomical reconstruction restored the biomechanical stability of the SMCL- and POL-deficient knee. Compared with anatomical reconstruction, triangular reconstruction can largely restore the stability of the knee joint. There were small differences between anatomical reconstruction and triangular reconstruction, which can likely be ignored.

MCL injury is the most common ligament injury of the medial knee joint. Isolated sMCL injuries often heal with appropriate conservative treatment [3, 22]. However, they are frequently found to be accompanied by POL injuries $[4,15]$, and conservative management of these combined injuries may lead to functional limitations and osteoarthritis [6]. Therefore, simultaneous operative treatment of the sMCL and POL is necessary in some circumstances.

The MCL plays an important role in the movement of the knee joint (valgus, external rotation, and internal rotation), especially in valgus [12]. The POL is

Table 2 External rotation with the application of an externally applied load for each testing state

\begin{tabular}{llllll}
\hline Flexion angles & $0^{\circ}$ & $20^{\circ}$ & $30^{\circ}$ & $60^{\circ}$ & $90^{\circ}$ \\
\hline Intact & $9.64 \pm 0.88$ & $14.36 \pm 1.91$ & $14.74 \pm 0.88$ & $16.00 \pm 0.72$ & $18.34 \pm 1.41$ \\
Deficient & $13.18 \pm 0.99^{*}$ & $20.30 \pm 2.01^{*}$ & $20.95 \pm 0.58^{*}$ & $25.91 \pm 0.76^{*}$ & $29.03 \pm 0.48^{*}$ \\
Triangular & $9.97 \pm 1.00$ & $15.32 \pm 2.06$ & $15.34 \pm 1.06$ & $16.55 \pm 0.48$ & $18.18 \pm 1.07$ \\
Anatomical & $10.13 \pm 0.51$ & $16.28 \pm 3.32$ & $14.70 \pm 1.08$ & $16.61 \pm 1.00$ & $17.93 \pm 1.06$ \\
\hline
\end{tabular}

Values are presented as mean \pm standard error of the mean

*Significant difference compared with the Intact group $(p<0.05)$ 
Table 3 Internal rotation with the application of an externally applied load for each testing state

\begin{tabular}{llllll}
\hline Flexion angles & $0^{\circ}$ & $20^{\circ}$ & $30^{\circ}$ & $60^{\circ}$ & $90^{\circ}$ \\
\hline Intact & $9.74 \pm 0.31$ & $16.46 \pm 1.94$ & $16.05 \pm 0.35$ & $7.53 \pm 1.40$ & $12.14 \pm 0.47$ \\
Deficient & $15.87 \pm 0.46^{*}$ & $24.25 \pm 2.19^{*}$ & $17.94 \pm 0.44^{*}$ & $16.61 \pm 1.68^{*}$ & $13.78 \pm 0.74^{*}$ \\
Triangular & $10.13 \pm 0.74$ & $19.23 \pm 2.81^{*}$ & $15.95 \pm 0.58^{*}$ & $7.76 \pm 1.02$ & $12.46 \pm 0.55$ \\
Anatomical & $9.83 \pm 0.29$ & $17.27 \pm 2.76$ & $16.05 \pm 0.45$ & $7.43 \pm 1.09$ & $12.61 \pm 0.87$ \\
\hline
\end{tabular}

Values are presented as mean \pm standard error of the mean

*Significant difference compared with the Intact group $(p<0.05)$

${ }^{\S}$ Significant difference compared triangular groups with the anatomical group $(p<0.05)$

complementary to the $\mathrm{MCL}$, and also plays a role in valgus $[12,23-25]$. The valgus angles of the tested knees increased significantly after cutting off the MCL and POL. This experiment confirmed the important role of the sMCL and the POL in the valgus stability of the knee joint, as observed in previous studies [12, 17]. Studies have demonstrated that the sMCL provides $78 \%$ of the restraining force against valgus power at $25^{\circ}$ of knee flexion $[4,8,14]$. Simultaneously, an obvious increase $\left(10.25^{\circ}\right)$ in valgus was observed at $20^{\circ}$ of knee flexion with sectioning of the medial knee structures. The sMCL and POL also have important roles in rotational stability [12]. Sectioning of the SMCL and POL also resulted in a significant increase in external rotation and internal rotation of the tibia at several different knee flexion angles $\left(0^{\circ}, 20^{\circ}, 30^{\circ}, 60^{\circ}\right.$, and $\left.90^{\circ}\right)$.

The recovery of anatomical structures and biomechanical function of the knee must be considered when creating a therapy program. An anatomically reconstructed knee has been shown to lead to biomechanics similar to that of a normal knee joint $[18,20,26]$. Our experimental model confirmed that anatomical reconstruction can not only effectively restore anatomical structures but can also effectively restore the biomechanics of the knee

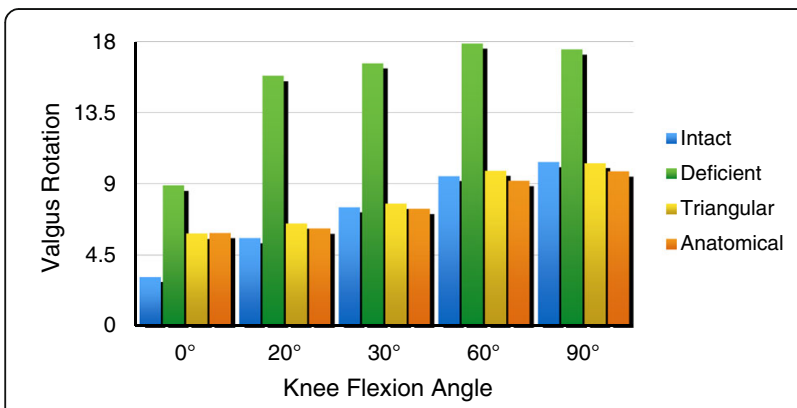

Fig. 4 The changes in the knee joint of each group were observed under a force of $10 \mathrm{~N} . \mathrm{m}$. After initial sectioning of the $\mathrm{SMCL}$ and $\mathrm{POL}$, we observed significantly increased valgus rotation at all knee flexion angles. In addition, a significant decrease was observed after $S M C L$ and POL reconstruction compared with the deficient $S M C L$ and POL states at all knee flexion angles. A significant increase was observed in valgus angulation of the anatomically reconstructed knee compared with the intact reconstruction at $0^{\circ}$ of knee flexion. The mean valgus angulation with the triangular reconstruction was significantly different from the normal knee at $0^{\circ}$ of knee flexion joint. There were no obvious differences between the intact and the anatomically reconstructed knees at knee flexion angles of $20^{\circ}, 30^{\circ}, 60^{\circ}$, and $90^{\circ}$. The results of this study are similar to those reported by Coobs [18]. Only partial valgus relaxation remained at $0^{\circ}$ of knee flexion. The triangular reconstruction technique was performed due to the femoral attachments of the SMCL and the POL being in close proximity [21]. The femoral attachments of the sMCL and the POL were merged as a single reconstruction point $(\mathrm{sMCL})$, and the tibial attachments of the sMCL and POL remained at their anatomical attachment points in this experimental model. In order to evaluate the effectiveness of triangular reconstruction of the sMCL and POL, this study tested static knee stability before and after ligament reconstruction, and compared the stability following the triangular and anatomical reconstructions compared with the normal knee. The triangular medial knee reconstruction technique provided a full recovery to native stability at $0^{\circ}, 60^{\circ}$, and $90^{\circ}$ of knee flexion. A small but significant increase was found in tibial internal rotation of the triangular reconstruction knee as compared with the intact knee $\left(2.77^{\circ}\right.$ and $0.99^{\circ}$ at $20^{\circ}$ and $30^{\circ}$ of knee flexion, respectively). Although we did find small differences in internal rotation at $20^{\circ}$ and $30^{\circ}$ of knee flexion, we believe these differences were not clinically significant. Compared with the anatomical reconstruction, a small difference $\left(0.93^{\circ}\right)$ in internal rotation was found at $30^{\circ}$ of knee flexion. This was due to the significant role of

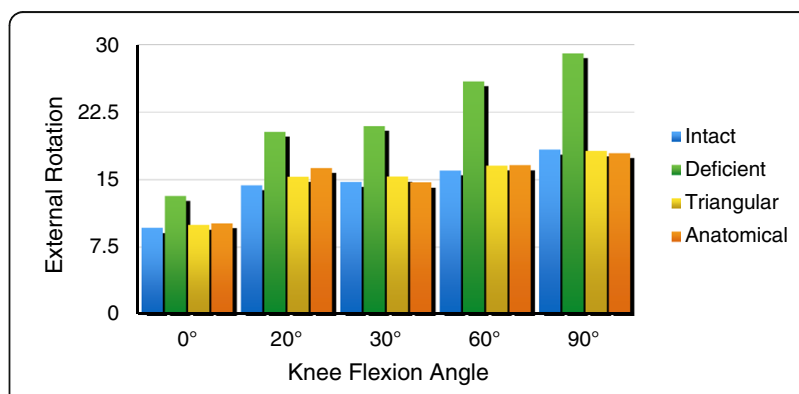

Fig. 5 The changes in the knee joint of each group were observed under a force of $5 \mathrm{~N} . \mathrm{m}$. We found a significant increase in external rotation after sectioning the $\mathrm{SMCL}$ and $\mathrm{POL}$ at all tested knee flexion angles. In addition, a significant decrease was observed in knees with the $S M C L$ and POL reconstruction compared with the SMCL- and POL-deficient knees at all angles of knee flexion 


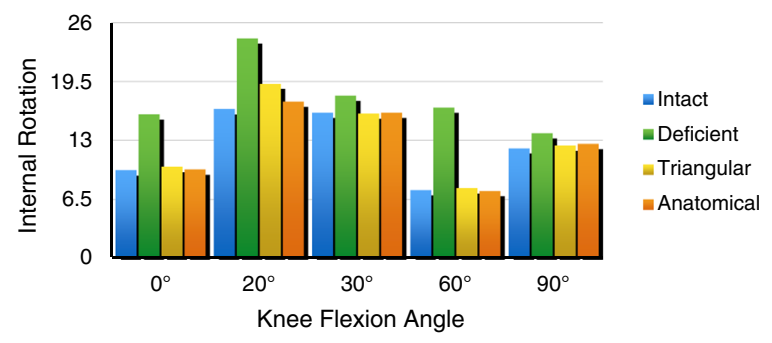

Fig. 6 The changes in the knee joint of each group were observed under a force of $5 \mathrm{~N} . \mathrm{m}$. After initial sectioning of the $\mathrm{SMCL}$ and POL, we observed significantly increased internal rotation at all knee flexion angles $\left(0^{\circ}, 20^{\circ}, 30^{\circ}, 60^{\circ}, 90^{\circ}\right)$. A significant increase was observed in internal rotation of the triangular reconstruction compared with the intact reconstruction at knee flexion angles of $20^{\circ}$ and $30^{\circ}$. The mean value of internal rotation with the anatomical reconstruction changed significantly compared with the normal knee at $30^{\circ}$ of knee flexion

the POL in internal rotation stability of the knee joint [10]. The majority of rotational stability was restored after triangular reconstruction. Furthermore, it also reduced the amount of hardware used in the internal fixation.

This study had inherent limitations. Our sample size was small, although it was powered to show statistical differences between groups. This experiment did not simulate muscle tension and only involved static biomechanical tests. Another limitation was that we did not verify the clinical effectiveness of this method.

\section{Conclusion}

This study suggests that anatomical SMCL and POL reconstruction may produce slightly better biomechanical stability than the triangular reconstruction, but the triangular reconstruction may restore a near-normal knee joint, and is both less invasive and more practical.

\section{Abbreviations}

MCL: Medial collateral ligament; POL: Posterior oblique ligament; sMCL: Superficial medial collateral ligament

\section{Acknowledgements}

We thank Peter Mittwede, MD, PhD, from Liwen Bianji, Edanz Editing China (www.liwenbianji.cn), for editing the English text of a draft of this manuscript.

\section{Availability of data and materials}

The datasets generated and/or analyzed during the current study are not publicly available because they contain patients' personal information, but are available from the corresponding author on reasonable request.

\begin{abstract}
Authors' contributions
XMW designed the study and drafted the manuscript. HXL carried out the acquisition and interpretation of the data. GMD acquired the data and drew the schematic diagrams. YZN and CL carried out follow-up and measurements. FW performed the surgeries and revised the manuscript critically. All authors read and approved of the final manuscript.
\end{abstract}

\section{Ethics approval and consent to participate}

The clinical study proposal was approved by the Ethical Committee of the Third Hospital of Hebei Medical University. Informed consent to participate in the study was obtained from the patients, and written consent was obtained from the patients before they died to use their knees after death.

\section{Competing interests}

The authors declare that they have no competing interests.

\section{Publisher's Note}

Springer Nature remains neutral with regard to jurisdictional claims in published maps and institutional affiliations.

Received: 14 September 2017 Accepted: 4 April 2018

Published online: 20 April 2018

\section{References}

1. Ballmer PM, Jakob RP. The non operative treatment of isolated complete tears of the medial collateral ligament of the knee. A prospective study. Arch Orthop Trauma Surg. 1988;107(5):273-6.

2. Ellsasser JC, Reynolds FC, Omohundro JR. The non-operative treatment of collateral ligament injuries of the knee in professional football players. An analysis of seventy-four injuries treated non-operatively and twenty-four injuries treated surgically. J Bone Joint Surg Am. 1974;56(6):1185-90.

3. Indelicato PA. Non-operative treatment of complete tears of the medial collateral ligament of the knee. J Bone Joint Surg Am. 1983;65(3):323-9.

4. Hughston JC, Eilers AF. The role of the posterior oblique ligament in repairs of acute medial (collateral) ligament tears of the knee. J Bone Joint Surg Am. 1973;55(5):923-40.

5. Halinen J, Lindahl J, Hirvensalo E, Santavirta S. Operative and nonoperative treatments of medial collateral ligament rupture with early anterior cruciate ligament reconstruction: a prospective randomized study. Am J Sports Med. 2006;34(7):1134-40.

6. Kannus P. Long-term results of conservatively treated medial collateral ligament injuries of the knee joint. Clin Orthop Relat Res. 1988;226:103-12.

7. Yoshiya S, Kuroda R, Mizuno K, Yamamoto T, Kurosaka M. Medial collateral ligament reconstruction using autogenous hamstring tendons: technique and results in initial cases. Am J Sports Med. 2005;33(9):1380-5.

8. Grood ES, Noyes FR, Butler DL, Suntay WJ. Ligamentous and capsular restraints preventing straight medial and lateral laxity in intact human cadaver knees. J Bone Joint Surg Am. 1981;63(8):1257-69.

9. Warren LA, Marshall JL, Girgis F. The prime static stabilizer of the medical side of the knee. J Bone Joint Surg Am. 1974;56(4):665-74.

10. Griffith CJ, Wijdicks CA, LaPrade RF, Armitage BM, Johansen S, Engebretsen L. Force measurements on the posterior oblique ligament and superficial medial collateral ligament proximal and distal divisions to applied loads. Am J Sports Med. 2009;37(1):140-8.

11. Haimes $J$, Wroble RR, Grood ES, Noyes FR. Role of the medial structures in the intact and anterior cruciate ligament-deficient knee. Limits of motion in the human knee. Am J Sports Med. 1994:22(3):402-9.

12. Griffith CJ, LaPrade RF, Johansen S, Armitage B, Wijdicks C, Engebretsen L. Medial knee injury: part 1, static function of the individual components of the main medial knee structures. Am J Sports Med. 2009;37(9):1762-70.

13. Butler DL, Noyes FR, Grood ES. Ligamentous restraints to anterior-posterior drawer in the human knee. A biomechanical study. J Bone Joint Surg Am. 1980;62(2):259-70.

14. Slocum DB, Larson RL. Rotatory instability of the knee. Its pathogenesis and a clinical test to demonstrate its presence. J Bone Joint Surg Am. 1968;50(2):211-25.

15. Hughston JC. The importance of the posterior oblique ligament in repairs of acute tears of the medial ligaments in knees with and without an associated rupture of the anterior cruciate ligament. Results of long-term follow-up. J Bone Joint Surg Am. 1994;76(9):1328-44.

16. Fanelli GC, Harris JD. Surgical treatment of acute medial collateral ligament and posteromedial corner injuries of the knee. Sports Med Arthrosc. 2006;14(2):78-83.

17. Lind M, Jakobsen BW, Lund B, Hansen MS, Abdallah O, Christiansen SE. Anatomical reconstruction of the medial collateral ligament and posteromedial corner of the knee in patients with chronic medial collateral ligament instability. Am J Sports Med. 2009:37(6):1116-22.

18. Coobs BR, Wijdicks CA, Armitage BM, Spiridonov SI, Westerhaus BD, Johansen $\mathrm{S}$, et al. An in vitro analysis of an anatomical medial knee reconstruction. Am J Sports Med. 2010;38(2):339-47. 
19. Azar FM. Evaluation and treatment of chronic medial collateral ligament injuries of the knee. Sports Med Arthrosc. 2006;14(2):84-90.

20. Feeley BT, Muller MS, Allen AA, Granchi CC, Pearle AD. Isometry of medial collateral ligament reconstruction. Knee Surg Sports Traumatol Arthrosc. 2009;17(9):1078-82.

21. LaPrade RF, Engebretsen AH, Ly TV, Johansen S, Wentorf FA, Engebretsen L. The anatomy of the medial part of the knee. J Bone Joint Surg Am. 2007;89(9):2000-10.

22. Reider B, Sathy MR, Talkington J, Blyznak N, Kollias S. Treatment of isolated medial collateral ligament injuries in athletes with early functional rehabilitation. A five-year follow-up study. Am J Sports Med. 1994;22(4):470-7.

23. Wijdicks CA, Griffith CJ, LaPrade RF, Spiridonov SI, Johansen S, Armitage BM, et al. Medial knee injury: part 2, load sharing between the posterior oblique ligament and superficial medial collateral ligament. Am J Sports Med. 2009;37(9):1771-6

24. Wijdicks CA, Griffith CJ, Johansen S, Engebretsen L, LaPrade RF. Injuries to the medial collateral ligament and associated medial structures of the knee. J Bone Joint Surg Am. 2010;92(5):1266-80.

25. Robinson JR, Bull AM, Thomas RR, Amis AA. The role of the medial collateral ligament and posteromedial capsule in controlling knee laxity. Am J Sports Med. 2006;34(11):1815-23.

26. Borden PS, Kantaras AT, Caborn DN. Medial collateral ligament reconstruction with allograft using a double-bundle technique. Arthroscopy. 2002;18(4):E19

Ready to submit your research? Choose BMC and benefit from:

- fast, convenient online submission

- thorough peer review by experienced researchers in your field

- rapid publication on acceptance

- support for research data, including large and complex data types

- gold Open Access which fosters wider collaboration and increased citations

- maximum visibility for your research: over $100 \mathrm{M}$ website views per year 